\title{
The Association Between Abnormal Vaginal Flora and Cytological Evidence of HPV with Prematurity in High-Risk Pregnant Women
}

\author{
Alana Dantas FREIRE', Ada Isa CUSTÓDIO', José Queiroz FILHO², Janaína Crispim FREITAS², \\ Ana Katherine GONÇALVES ${ }^{3}$, Ricardo Ney COBUCCI ${ }^{4}$
}

Natal, Brazil

\begin{abstract}
OBJECTIVE: To evaluate the association between abnormal vaginal flora and cytological evidence of HPV with prematurity in high-risk pregnant women.

STUDY DESIGN: A prospective cohort study was designed with high-risk pregnant women who delivered singletons between 20-42 gestational weeks between January to November 2018. Vaginal specimens were collected to obtain material from the upper lateral vaginal vault and cervix for direct microscopic examination of vaginal contents and preparation of Gram-stained and pap smear slides. Potential determinants of infection were assessed using the chi-square test. Poisson regression was used to determine the prevalence ratio and $95 \%$ confidence interval of the association between the vaginal flora and cytology with prematurity and a $p<0.05$ was considered as statistical significance.

RESULTS: A total of 68 pap smear and high vaginal swab samples were collected from high-risk pregnant women with a mean age of 30.3 years. There were $26(38.2 \%)$ cases of abnormal vaginal flora and $6(8.8 \%)$ of HPV-induced cytological abnormalities. The preterm delivery rate was comparable between women with normal and abnormal vaginal flora (11.9\% vs. $11.5 \%$, prevalence ratio 1.0 [95\% confidence interval: 0.8-1.2], aPR 1.0 [95\% confidence interval: 0.8-1.2]) and between women with and without abnormal cytology $(16.7 \%$ vs. $11.3 \%$, prevalence ratio 0.9 [95\% confidence interval: $0.6-1.4]$, aPR 0.9 [95\% confidence interval: 0.6-1.4]).
\end{abstract}

CONCLUSIONS: We determined no association between abnormal cytology or altered vaginal flora in high-risk pregnancy in terms of overall preterm birth rate.

Keywords: High-risk, Papanicolaou test, Pregnancy, Vaginal infection

Gynecol Obstet Reprod Med 2020;26(3):173-178

${ }^{I}$ Federal University of Rio Grande do Norte (UFRN), Natal, Brazil

2 Department of Clinical and Toxicological Analysis, Federal University of Rio Grande do Norte (UFRN), Natal, Brazil

${ }^{3}$ Postgraduate program in Health Sciences, Federal University of Rio Grande do Norte (UFRN), Natal, Brazil

${ }^{4}$ Postgraduate program in Biotechnology and Medicine School, Potiguar University (UnP), Natal, Brazil

Address of Correspondence: Ricardo Ney Cobucci

Potiguar University (UnP),

Salgado Filho Av., 1610, Natal - RN, Zip

code 59056-000, Brazil

rncobucci@unp.br

Submitted for Publication:

26.01.2019

08.03 .2019

Accepted for Publication: $\quad 20.05 .2019$

ORCID IDs of the authors:

ADF: 0000-0003-1720-968X, AIC: 0000-0002-8138-5840

JQF: 0000-0003-3405-7008, JCF: 0000-0002-1344-0078

$A K G$ : 0000-0002-8351-5119, RNC: 0000-0002-0184-2061

\begin{tabular}{c|c}
\hline Quick Response Code: & Access this article online \\
\cline { 2 - 2 } & Website: www.gorm.com.tr \\
& e- mail: info@gorm.com.tr \\
\hline & DOI:10.201613/GORM.2019.928
\end{tabular}

How to cite this article: Freire AD. Custódio AI. Filho JQ. Freitas JC. Gonçalves AK. Cobucci RN. The Association between Abnormal Vaginal Flora and Cytological Evidence of HPV with Prematurity in High-Risk Pregnant Women. Gynecol Obstet Reprod Med. 2020;26(3):173-178

\section{Introduction}

The vaginal microbiome plays a key role in maternal and neonatal health. The imbalance in this microbiome (dysbiosis) in pregnancy is associated with severe outcomes such as abortion and preterm labor, but the underlying mechanisms remain poorly understood (1). Moreover, recent evidence suggests that microbiome niches in pregnancy are not limited to maternal body sites, since a low biomass microbiome presumably formed in the early stages of gestation has been identified in the placenta, with studies indicating that it may have an association with prematurity (2).

In high-risk pregnant women with diseases such as hypertension and diabetes, amongst others, the risk of miscarriage, preterm delivery, and chorioamnionitis is higher only because of comorbidities. In this way, the importance of the normal microbiome composed of the Lactobacillus species, which inhibits the growth of bacteria and fungi in the vagina, is enhanced by the maintenance of $\mathrm{pH}$ acidity and the production of compounds such as hydrogen peroxide and bacteriocins $(3,4)$. 
The association of bacterial vaginosis and trichomoniasis with prematurity and premature rupture of membranes is already well established; however, recent studies have indicated that pregnant women with cytological abnormalities are also at higher risk of preterm birth $(4,5)$. Thus, studies evaluating the association of HPV-induced cytological lesions and vulvovaginitis (VV) with these outcomes are important to verify if these changes in vaginal microbiome are linked with prematurity in high-risk pregnancies.

However, most studies evaluating the prevalence of these genital infections are performed in low-risk pregnant women (4-10). The objective of this study is to evaluate the association between abnormal vaginal flora and cytological evidence of HPV with prematurity in high-risk pregnant women.

\section{Materials and Methods}

This study was performed at a high-risk prenatal outpatient clinic of a Brazilian University Hospital, a reference in attending high-risk pregnancies. This is a prospective cohort study of high-risk pregnant women who delivered singletons between 20 and 42 completed weeks of gestation from January to November 2018. Approval was granted by the Teaching Hospital Ethics Committee. The study was conducted in accordance with the Declaration of Helsinki.

This research was conducted on the pregnant women who visited the Maternity Hospital for routine antenatal care, independent of the presence or absence of symptoms of VV. All women involved in the research signed a term of consent in which they declared their knowledge that the collected material would be used for research, they answered a standard questionnaire on their personal data such as age, trimester of gestation, clinical and obstetric history of medical concerns and were subjected to routine prenatal screening with serologies for syphilis, HIV, toxoplasmosis and Hepatitis B. Subjects were excluded for the following reasons: vaginal bleeding; current antibiotics or vaginal medication use in the 30 days prior to sample collection, or sexual intercourse or a vaginal procedure in the $72 \mathrm{~h}$ preceding the examination and had not had delivery during the study period.

Vaginal specimens were collected using sterile cotton swabs to obtain material from the upper lateral vaginal vault with the aid of a disposable vaginal speculum for direct microscopic examination of vaginal contents and for preparation of Gram-stained slides: swabs were made on previously identified matte glass slides and after drying were fixated in moderate heat. After fixation, the smears were covered with violet crystal, taking care to place the dye at one end of the slide and allowing it to drain on the smear for one minute. Then the violet crystal that was on the smear was drained, and the lugol (mordant substance) was put on the smear for one minute. The lugol that was on the smears was discarded and the process of differentiation with alcohol at $95^{\circ}$ began until all excess of gentian violet was removed. The stained smear was covered with Gram stain Fuchsin for 30 seconds, washed with distilled water, dried with filter paper and analyzed by light microscopy on immersion lenses (X100).

The diagnosis of Trichomonas vaginalis (TV) was based on the presence of mobile flagellated protozoa in wet mount microscopy. Vulvovaginal candidiasis (VVC) was diagnosed by the presence of blastoconidia or pseudohyphae and neutrophils in the microscopy exam of the vaginal content stained by Gram's method. Bacterial vaginosis (BV) and intermediate vaginal flora were diagnosed by Gram stain using the criteria by Nugent et al. (11). The Nugent score evaluated as follows: The decrease in large Gram positive rods; Lactobacillus spp. were scored as 0-4. Gram variable small rods, G. vaginalis, were scored as 0-4, whereas curved Gram variable rods, Mobilincus, spp., scored as 0-2. Scores summed, and results graded as 0-3 (normal vaginal flora), 4-6 (intermediate flora), and 7-10 (BV) (11). All stained slides were read by only one experienced cytologist who was blinded to the clinical data.

All the pregnant women underwent cervical cytological screening that was performed by a conventional cytology test (Pap smear). All specimens were submitted to the Department of Pathology at the University Hospital, where they were read by a certified cytopathologist to obtain accurate diagnoses using the Bethesda System 2014 criteria (12).

The criterion used to consider abnormal vaginal flora in the pregnant woman was the confirmation of the diagnosis of at least one or two VV-causing microorganisms in the mentioned exams. Pregnant women were classified into two groups, 'abnormal cytology' and 'normal cytology'. The 'abnormal cytology' group included women with an abnormal Pap test, this included atypical squamous cells of undetermined significance (ASC-US), atypical squamous cells which cannot rule out high-grade lesions (ASC-H), low-grade squamous intraepithelial lesion (LSIL) and high-grade squamous intraepithelial lesion (HSIL). The primary outcome was preterm delivery, which was defined as delivery at less than $37+0$ weeks of gestation.

The normal distribution of the age was verified by the Kolmogorov-Smirnov test and the descriptive data presented in mean and standard deviation. Potential determinants of infections including parity, comorbidities, diagnosis of syphilis, or HIV were assessed using chi-square test. Fisher's exact test was used when data in cross-tabulations were sparse or unbalanced $(n<5)$. Both tests were followed by multiple comparison of the Z-Test. Poisson regression with a robust estimator was used to determine the prevalence ratio (PR) and 95\% confidence interval (CI) of the association between the vaginal flora and cytology with prematurity. In addition, regression models adjusted for vaginal flora and cytology were tested. We report unadjusted and adjusted PR of Poisson regression models. All analyses were performed using the statistical 
package SPSS version $25.0\left(\right.$ IBM $^{\circledR}$, Chicago, IL, USA) and a $p<0.05$ was considered as statistical significance.

\section{Results}

A total of sixty-eight (68) Pap Smears and high vaginal swabs samples were collected from high-risk pregnant women within the age range of 18-44 years and with a mean age of 30.3 years. There were $26(38.2 \%)$ cases of abnormal vaginal flora among these women as shown in table 1 Eighteen (26.5\%) had VVC, ten (14.7\%) were positive for BV, three had VVC and BV, while only one (1.5\%) had trichomoniasis. There was no difference between pregnant women with normal and altered vaginal flora in terms of existence of obstetric complications such as gestational diabetes mellitus or preeclampsia.
The demographic data of the participants distributed by the cervical cytology results are shown in table I. There were only six cases of abnormal cervical cytology. There were four $(5.8 \%)$ and two $(2.9 \%)$ cases of LSIL and HSIL, respectively (Table II). There was no significant difference between the profile of pregnant women with normal and abnormal cytology.

The preterm delivery rate was comparable between women with normal and abnormal vaginal flora (11.9\% vs. 11.5\%, PR 1.0 [95\% CI: 0.8-1.2], aPR 1.0 [95\% CI: 0.8-1.2]) and between women with and without abnormal cytology (16.7\% vs. $11.3 \%$, PR 0.9 [95\% CI: 0.6-1.4], aPR 0.9 [95\% CI: 0.6-1.4])] (Table III).

Table I: Demographic data of the study population

\begin{tabular}{|c|c|c|c|c|c|c|}
\hline & $\begin{array}{c}\text { Normal } \\
\text { Vaginal } \\
\text { flora } \\
(n=42)\end{array}$ & $\begin{array}{l}\text { Abnormal } \\
\text { Vaginal } \\
\text { flora } \\
(n=26)\end{array}$ & $p$ & $\begin{array}{l}\text { Normal } \\
\text { Cytology } \\
(\mathrm{n}=62)\end{array}$ & $\begin{array}{c}\text { Abnormal } \\
\text { Cytology } \\
(n=6)\end{array}$ & $p$ \\
\hline Age (mean/SD) & $30.1 \pm 6.9$ & 30.56 .4 & 0.792 & $30.5 \pm 6.8$ & $28.2 \pm 5.2$ & 0.422 \\
\hline \multicolumn{7}{|l|}{ Parity, n (\%) } \\
\hline Nulliparous & $9(21.4)$ & $10(38.5)$ & 0.287 & $18(29.0)$ & $1(16.7)$ & 0.721 \\
\hline $1-3$ & $31(73.8)$ & $16(61.5)$ & & $42(67.7)$ & $5(83.3)$ & \\
\hline$>3$ & $2(4.8)$ & $0(0.0)$ & & $2(3.2)$ & $0(0.0)$ & \\
\hline Total & $42(100.0)$ & $26(100.0)$ & & $62(100.0)$ & $6(100.0)$ & \\
\hline \multicolumn{7}{|c|}{ Chronic Hypertension, n (\%) } \\
\hline Yes & $13(31.0)$ & $5(19.2)$ & 0.287 & $15(24.2)$ & $3(50.0)$ & 0.330 \\
\hline No & $29(69.0)$ & $21(80.0)$ & & $47(75.8)$ & $3(50.0)$ & \\
\hline Total & $42(100.0)$ & $26(100.0)$ & & $62(100.0)$ & $6(100.0)$ & \\
\hline \multicolumn{7}{|c|}{ Preeclampsia, n (\%) } \\
\hline Yes & $5(11.9)$ & $7(26.9)$ & 0.189 & $11(17.7)$ & $1(16.7)$ & 1.000 \\
\hline No & $37(88.1)$ & $19(73.1)$ & & $51(82.3)$ & $5(83.3)$ & \\
\hline Total & $42(100.0)$ & $26(100.0)$ & & $62(100.0)$ & $6(100.0)$ & \\
\hline \multicolumn{7}{|c|}{ Diabetes Mellitus, $\mathbf{n}(\%)$} \\
\hline Yes & $2(4.8)$ & $4(15.4)$ & 0.193 & $6(9.7)$ & $0(0.0)$ & 1,000 \\
\hline No & $40(95.2)$ & $22(84.6)$ & & $56(90.3)$ & $6(100.0)$ & \\
\hline Total & $42(100.0)$ & $26(100.0)$ & & $62(100.0)$ & $6(100.0)$ & \\
\hline \multicolumn{7}{|c|}{ Gestational diabetes, $\mathrm{n}(\%)$} \\
\hline Yes & $12(28.6)$ & $10(38.5)$ & 0,397 & $21(33.9)$ & $1(16.7)$ & 0,656 \\
\hline No & $30(71.4)$ & $16(61.5)$ & & $41(66.1)$ & $5(83.3)$ & \\
\hline Total & $42(100.0)$ & $26(100.0)$ & & $62(100.0)$ & $6(100.0)$ & \\
\hline \multicolumn{7}{|c|}{ Other Comorbidities, n (\%) } \\
\hline Yes & $33(78.6)$ & $16(61.5)$ & 0.128 & $44(71.0)$ & $5(83.3)$ & 1,000 \\
\hline No & $9(21.4)$ & $10(38.5)$ & & $18(29.0)$ & $1(16.7)$ & \\
\hline Total & $42(100.0)$ & $6(100.0)$ & $62(100.0)$ & $6(100.0)$ & & \\
\hline \multicolumn{7}{|l|}{ HIV, n (\%) } \\
\hline Yes & $1(2.4)$ & $0(0.0)$ & 1.000 & $1(1.6)$ & $0(0.0)$ & 1,000 \\
\hline No & 41 (97.6) & $26(100.0)$ & & $61(98.4)$ & $6(100.0)$ & \\
\hline Total & $42(100.0)$ & $26(100.0)$ & & $62(100.0)$ & $6(100.0)$ & \\
\hline \multicolumn{7}{|l|}{ Syphilis, n (\%) } \\
\hline Yes & $2(4.8)$ & $1(3.8)$ & 1.000 & $3(4.8)$ & $0(0.0)$ & 1.000 \\
\hline No & $40(95.2)$ & $25(96.2)$ & & $59(95.2)$ & $6(100.0)$ & \\
\hline Total & $42(100.0)$ & $26(100.0)$ & & $62(100.0)$ & $6(100.0)$ & \\
\hline
\end{tabular}


Table II: Distribution of Gram stain and Pap test results in 68 high-risk pregnant women

\begin{tabular}{lc}
\hline Diagnostic method & $\mathrm{n}(\%)$ \\
\hline Vaginal flora (Gram stain) & $42(61.8)$ \\
$\quad$ Normal & $26(38.2)$ \\
Altered & $68(100.0)$ \\
$\quad$ Total & $18(26.5)$ \\
Microorganisms & $50(73.5)$ \\
VVC & $10(14.7)$ \\
Yes & $58(85.3)$ \\
No & $1(1.5)$ \\
Gardnerella vaginalis & $67(98.5)$ \\
Yes & \\
No & \\
Trichomonas vaginalis & $62(91.2)$ \\
Yes & $4(5.9)$ \\
No & $2(2.9)$ \\
Nytology (Pap smear) & \\
LSIL & \\
HSIL & \\
\hline
\end{tabular}

VVC: Vulvovaginal candidiasis, NILM: Negative for intraepithelial lesion and malignancy, LSIL: Low-grade squamous intraepithelial lesion, HSIL: High-grade squamous intraepithelial lesion.

Table III: Association between altered vaginal flora and abnormal cytology as predictors of prematurity

\begin{tabular}{llcc|ccc}
\hline & \multicolumn{3}{c|}{ Unadjusted } & \multicolumn{3}{c}{ Adjusted } \\
\cline { 2 - 6 } & PR & Cl 95\% & p & aPR & Cl 95\% & p \\
\hline Vaginal flora & 1.0 & $0.8-1.2$ & 0.964 & 1.0 & $0.8-1.2$ & 0.958 \\
Cytology & 0.9 & $0.6-1.4$ & 0.740 & 0.9 & $0.6-1.4$ & 0.737 \\
\hline
\end{tabular}

PR: Prevalence ratio, Cl: Confidence interval, aPR: Adjusted prevalence ratio

\section{Discussion}

Candidiasis and bacterial vaginosis were the most commonly diagnosed genital infections in our study cohort. HPVinduced cytological abnormalities were found in less than ten percent, a similar frequency to that found in non-pregnant women. In addition, pregnant women with abnormal cytology and flora did not present a higher prevalence ratio for prematurity.

Limited data exist on VV prevalence in high-risk pregnant women. Most of the studies evaluated the prevalence of vaginal flora alterations in pregnant women with low-risk pregnancies, such as the studies performed in Argentina by Mucci et al. in which $33 \%$ presented VVC, $18 \% \mathrm{BV}$ and $1.4 \% \mathrm{TV}$ and the studies in Greece by Tansarli et al. who found $50 \%$ of pregnant women with candidiasis, $10 \%$ with bacterial vaginosis and $0.4 \%$ with trichomoniasis $(13,14)$.

In Brazil, similar studies were performed, but only among low-risk pregnant women where Gondo et al. found altered vaginal flora in $45.7 \%$ of the subjects, with a prevalence of bacterial vaginosis of $21.6 \%$ and vaginal candidiasis of $10.2 \%$, whereas in another study with 120.000 women BV was diagnosed in $20 \%$ and VVC in $11.8 \%(15,16)$

Recent studies have examined the role of the vaginal microbiome and possible associations with preterm birth (17, 18). It has been proposed that the increased stability of the vaginal microbiome during pregnancy can influence the prevention of ascending vaginal infection by maintenance of vaginal $\mathrm{pH}$ and the production of bactericidal substances provided by Lactobacilli. Disturbances in Lactobacilli often lead to dysbiosis and BV, a known risk factor for PTB (17). In a study involving 90 pregnant women Romero et al. found no association between altered vaginal flora and PTB (19). On the other hand, Hyman et al. affirm that the presence of bacteria in the vaginal microbiome was higher among women who had preterm labor (20).

Regarding the diagnosis of cytological abnormality, HSIL was not more frequent in women with high-risk pregnancies 
compared to non-pregnant women in this research, a result similar to that found in a Brazilian study (8). In this cohort study, only $6(8.8 \%)$ pregnant women presented LSIL or HSIL in conventional cytology, a result similar to that found by Khaengkhor et al. , Hong et al. and Nimrodi et al. (5, 21, 22). In the last two studies, as in this one, no association between cytological abnormality and prematurity was found.

The strength of this study is its prospective design. However, main limitation was sample size which was mostly due to the strict exclusion criteria and the need for follow-up until labor. Another limiting factor was the analysis of only a specific population from a Brazilian university hospital, preventing the findings from being extrapolated to other groups of high-risk pregnant women.

In conclusion, the most commonly diagnosed vaginal infections in this study were VVC and BV, whereas in the cytology evaluation HPV-induced abnormalities were less frequent. In addition, no association between abnormal cytology or altered vaginal flora in high-risk pregnant women and overall PTB was found.

Authors' contributions: The acquisition, analysis and interpretation of data were performed by ADF, AIC and JQF. The conception and design of the study were performed by RNC. JCF, $A K G$ and $R N C$ drafted the article or revising it critically for important intellectual content. All authors were responsible for the final approval of the version to be submitted.

Funding: This research did not receive any specific grant from funding agencies in the public, commercial, or not-for-profit sectors.

Competing interests: None declared.

\section{References}

1. Freitas AC, Chaban B, Bocking A, Rocco M, Yang S, Hill $\mathrm{JE}$, et al. The vaginal microbiome of pregnant women is less rich and diverse, with lower prevalence of Mollicutes, compared to non-pregnant women. Sci Rep. 2017;7(1): 9212. https://doi.org/10.1038/s41598-017-07790-9.

2. Prince AL, Chu DM, Seferovic MD, Antony KM, Ma J, Aagaard KM. The Perinatal Microbiome and Pregnancy: Moving Beyond the Vaginal Microbiome. Cold Spring Harb Perspect Med. 2015;5(6):a023051. https://doi.org/ 10.1101/cshperspect.a023051.

3. Yeruva T, Rajkumar H, Donugama V. Vaginal lactobacilli profile in pregnant women with normal \& abnormal vaginal flora. Indian J Med Res. 2017;146(4):534-40. https://doi.org/10.4103/ijmr.IJMR_774_16.

4. Giraldo PC, Araújo ED, Junior JE, do Amaral RL, Passos MR, Gonçalves AK. The prevalence of urogenital infections in pregnant women experiencing preterm and fullterm labor. Infect Dis Obstet Gynecol. 2012;2012:878241. http://dx.doi.org/10.1155/2012/878241.

5. Hong JN, Berggren EK, Campbell SL, Smith JS, Rahang- dale L. Abnormal Cervical Cancer Screening in Pregnancy and Preterm Delivery. Paediatr Perinat Epidemiol. 2014;28(4):297-301. https://doi.org/10.1111/ppe.12132.

6. Shrestha S, Tuladhar NR, Basnyat S, Acharya GP, Shrestha P, Kumar P. Prevalence of vaginitis among pregnant women attending Paropakar Maternity and Women's Hospital, Thapathali, Kathmandu, Nepal. Nepal Med Coll J. 2011;13(4):293-6.

7. Rathod S, Vijayalakshmi S. Prevalence of vaginitis during pregnancy and its fetomaternal outcome in the rural setup. Int J Reprod Contracept Obstet Gynecol 2016;5(6):18236. http://dx.doi.org/10.18203/2320-1770.ijrcog20161670.

8. Xavier-Júnior JCC, Dufloth RM, do Vale DB, Tavares TA, Zeferino LC. High-grade squamous intraepithelial lesions in pregnant and non-pregnant women. Eur J Obstet Gynecol Reprod Biol 2014;175:103-6. https:/doi.org/ 10.1016/j.ejogrb.2014.01.018.

9. He Y, Wu YM, Wang T, Song F, Wang Y, Zhu L. Perinatal outcomes of pregnant women with cervical intraepithelial neoplasia. Arch Gynecol Obstet. 2013;288(6): 1237-42. https://doi.org/10.1007/s00404-013-2889-6.

10. Mailath-Pokorny M, Schwameis R, Grimm C, Reinthaller A, Polterauer S. Natural history of cervical intraepithelial neoplasia in pregnancy: postpartum histo-pathologic outcome and review of the literature. BMC Pregnancy Childbirth. 2016;16:74. https://doi.org/10.1186/s12884-0160861-8.

11. Nugent RP, Krohn MA, Hillier SL. Reliability of diagnosing bacterial vaginosis is improved by a standardized method of gram stain interpretation. J Clin Microbiol. 1991;29(2):297-301.

12. Nayar R, Wilbur DC. The Pap Test and Bethesda 2014. Acta Cytol. 2015;59:121-32. https://doi.org/10.1159/ 000381842.

13. Mucci MJ, Cuestas ML, Cervetto MM, Landaburu MF, Mujica MT. A prospective observational study of vulvovagintis in pregnant women in Argentina, with special reference to candidiasis. Mycoses. 2016;59(7):429-35. https://doi.org/10.1111/myc.12490.

14. Tansarli GS, Skalidis T, Legakis NJ, Falagas ME. Abnormal vaginal flora in symptomatic non-pregnant and pregnant women in a Greek hospital: a prospective study. Eur J Clin Microbiol Infect Dis. 2017;36(2):227-32. https:// doi.org/10.1007/s10096-016-2787-5.

15. Gondo F, da Silva MG, Polettini J, Tristao A da R, Peracoli JC, Witkin SS, et al. Vaginal flora alterations and clinical symptoms in low-risk pregnant women. Gynecol Obstet Invest. 2011;71:158-62. https://doi.org/10.1159/ 000316051.

16. Gondo DC, Duarte MT, da Silva MG, de Lima Parada CM. Abnormal Vaginal Flora in Low-Risk Pregnant Women Cared for by a Public Health Service: prevalence and Association with Symptoms and Findings from Gynecological Exams. Rev Lat Am Enfermagem. 
2010;18(5):919-27. http://dx.doi.org/10.1590/S0104-1169 2010000500012.

17. Fox C, Eichelberger K. Maternal microbiome and pregnancy outcomes. Fertil Steril. 2015;104(6):1358-63. https://doi.org/10.1016/j.fertnstert.2015.09.037.

18. Petricevic L, Domig KJ, Nierscher FJ, Sandhofer MJ, Fidesser M, Krondorfer I, et al. Characterisation of the vaginal Lactobacillus microbiota associated with preterm delivery. Sci Rep. 2014;4:5136. https://doi.org/10.1038/ srep05136.

19. Romero R, Hassan SS, Gajer P, Tarca AL, Fadrosh DW, Bieda J, et al. The vaginal microbiota of pregnant women who subsequently have spontaneous preterm labor and delivery and those with a normal delivery at term. Microbiome. 2014;2:18. https://doi.org/10.1186/2049-2618-2-18.
20. Hyman RW, Fukushima M, Jiang H, Fung E, Rand L, Johnson B, et al. Diversity of the vaginal microbiome correlates with preterm birth. Reprod Sci. 2014;21(1):32-40. https://doi.org/10.1177/1933719113488838.

21. Khaengkhor P, Mairaing K, Suwannarurk K, Thaweekul Y, Poomtavorn Y, Pattaraarchachai J, et al. Prevalence of abnormal cervical cytology by liquid based cytology in the antenatal care clinic, Thammasat University Hospital. J Med Assoc Thai. 2011;94(2):152-8.

22. Nimrodi M, Kleitman V, Wainstock T, Gemer O, Meirovitz M, Maymon E, et al. The association between cervical inflammation and histologic evidence of HPV in PAP smears and adverse pregnancy outcome in low risk population. Eur J Obstet Gynecol Reprod Biol. 2018;225: 160-5. https://doi.org/10.1016/j.ejogrb.2018. 04.023. 